\title{
CAMINHOS DA SUSTENTABILIDADE URBANA: O DESAFIO DA CONSTRUÇÃO DA GESTÃO DOS RISCOS SOCIOAMBIENTAIS URBANOS
}

\author{
Corina A. B. Carril Ribeiro*, Rafaela Antunes \\ Fortunato**, Claudia Cristina L. Machado $^{* * *}$
}

Resumo: Com a emergência dos debates ambientais, no século XX, pelo surgimento de inúmeros problemas socioambientais urbanos e rurais, nos âmbitos local, regional e global, a temática da sustentabilidade urbana tem ocupado o palco de constantes debates e estudos científicos, e estado presente mais fortemente enquanto elemento discursivo e ideológico do que em programas e ações praticadas na gestão urbana. O presente artigo visa apresentar a visão de diversos autores sobre o tema, em seguida discute a relação entre globalização e riscos, apontando a governança como elemento essencial para a gestão dos riscos socioambientais urbanos.

Palavras-chave: Sustentabilidade Urbana, Riscos Socioambientais Urbanos, Gestão Urbana, Governança.

Abstract: With the emergence of environmental debates in the twentieth century, due numerous urban and rural socio-environmental problems, at the local, regional and global scale, the theme of urban sustainability has been at the scene of constant debate and scientific studies, however more strongly as part discursive and ideological than in programs and activities practiced in urban management. This paper presents the view of several authors on the topic, then discusses the relationship between globalization and risks, pointing governance as essential for the management of urban environmental risk.

Keywords: Urban sustainability; Urban social and environmental risks; Urban management; Governance.

* Socióloga. Doutoranda em Meio Ambiente e Desenvolvimento pela UFPR. E-mail: carrilribeiro@yahoo.com.br.

** Arquiteta. Doutoranda em Meio Ambiente e Desenvolvimento pela UFPR. E-mail: rafortunato@utfpr.edu.br.

*** Relações Públicas. Doutoranda em Meio Ambiente e Desenvolvimento pela UFPR. E-mail: claudiacristina.machado@hotmail.com. 
$\mid 244$ |

Caminhos da sustentabilidade urbana: o desafio da construção..

\section{Introdução}

Muitos pesquisadores afirmam que hoje se vive urbanismo de resultados, das cidades sustentáveis edificadas de fora para dentro, artificialmente. Dentre estes autores, destaca-se Acselrad (2009), fonte inspiradora para a estruturação deste artigo.

As cidades contemporâneas, em tempos globalizados apresentam profunda desigualdade social, de acesso aos recursos naturais como água, saneamento, verde, solo seguro e da exposição aos riscos ambientais das moradias (e de seus moradores), em encostas perigosas, beiras de cursos d'água, etc.

A noção de sustentabilidade está submetida à lógica das práticas, enfatiza Acselrad. Para se ter autoridade para falar de sustentabilidade é preciso haver uma audiência apropriada, um campo de interlocução eficiente para que se possa encontrar aprovação.

A cidade sustentável, metáfora da cidade-empresa, articulada sobre égides de cidades modelo de qualidade de vida, cidades ecológicas, entre tantos outros arquétipos, escondem a insustentabilidade da administração pública, dos recursos públicos e das fragilidades da governança e da autogestão. A insustentabilidade, pois, exprime a incapacidade das políticas urbanas adaptarem a oferta de serviços urbanos à quantidade e qualidade das demandas sociais provocando um desequilíbrio entre necessidades cotidianas da população e os meios de as satisfazer, aumentando, desta forma, seus estados de vulnerabilidade, de risco e diminuindo suas resiliências.

$\mathrm{O}$ artigo em tela objetiva, portanto, discutir a temática da sustentabilidade urbana, especialmente no campo do planejamento e da gestão urbana das metrópoles, apresentando a opinião de especialistas, apontando a necessidade da articulação da gestão dos riscos associados às questões socioambientais contemporâneas.

\section{Sociedade de risco}

A análise histórica da transição da modernidade tradicional à pós-tradicional ou pós-industrial, no contexto dos séculos XIX 
ao $\mathrm{XX}$, evidencia que as certezas que a modernidade representava foram dissolvidas, assim como a crença no papel das instituições como o Estado, a Igreja, a Família, instaurando-se um cenário de incertezas e a preocupação com o risco, agora, inerente ao período pós-tradicional. Na segunda metade do século XX pesquisadores começam, então, a estudar as sociedades, para alguns, chamadas de Risco.

O conceito de sociedade do risco é introduzido por Beck (1998), que discute as tendências de desenvolvimento das práticas sociais, desde o pensamento da história social até os conceitos e variáveis relacionados à sociedade industrial. São tratados e entrelaçados na análise dois aspectos essenciais: a produção da riqueza, pela modernização e a produção dos riscos. No centro da discussão estão os riscos e consequências dessa modernização, os quais constituem ameaças irreversíveis à vida das plantas, animais e seres humanos.

Ao contrário dos riscos empresariais e profissionais do século XIX e da primeira metade do século XX, estes riscos já não se limitam a lugares e grupos, mas constituem uma tendência de globalização que abarca a produção e a reprodução e não respeita as fronteiras dos Estados Nacionais, surgindo ameaças globais que são supranacionais e não específicas de uma classe, possuindo uma dinâmica social e política nova. No entanto, essas ameaças sociais e seu potencial cultural e político são somente um dos lados da sociedade do risco (Beck, 1998).

Outro ponto abordado pelo pesquisador é a individualização da desigualdade social, com a destradicionalização das formas de vida da sociedade industrial do século XIX e primeira metade do século XX. Beck (1998) ressalta que o projeto da sociedade industrial está sendo tolerado por vários esquemas - classe, família pequena, trabalho profissional, compreensão de ciência, progresso e democracia - elementos construtivos de uma tradição industrial, cujas bases se quebram e/ou são suprimidas na modernização. Assim, as irritações históricas desencadeadas são consequência do êxito das modernizações que agora acabam se voltando contra 
$|246|$

Caminhos da sustentabilidade urbana: o desafio da construção..

a própria sociedade industrial. Essas mudanças nas bases da vida, vivenciadas na atualidade, acabam por constituir sociedade do risco:

\begin{abstract}
Estamos viviendo un cambio de las bases de la vida conforman el reverso de la sociedad del riesgo. El sistema de coordenadas en que descansan la vida y el pensamiento en la modernidad industrial (los ejes de família y trabajo, fe en la ciencia y en el progreso) empieza a oscilar, y surge um nuevo juego de oportunidades y riesgos, los contomos de la sociedad del riesgo. ¿Oportunidades? En ella también se reclaman los principios de la modernidad frente a su recorte en la sociedad industrial (Beck, 1998, p. 21).
\end{abstract}

Segundo Beck, a sociedade pós-industrial pode ser caracterizada por ser de risco e reflexiva ${ }^{1}$, ou seja, a sociedade tem a capacidade de refletir sobre suas ações e omissões e agir dentro deste contexto. É possível pensar em sustentabilidade urbana dentro do contexto da sociedade de risco? Entende-se que, para Beck, o fenômeno do risco é uma das constituintes do desenvolvimento, constructo e construtor da pós-modernidade e, desta forma, está presente nas cidades, mesmo nas autodenominadas cidades sustentáveis ou na, assim, adjetivadas por estudiosos do urbanismo.

\title{
3. Discussões sobre a Sustentabilidade Urbana na Sociedade de risco
}

Discutir sobre sustentabilidade urbana não é tarefa Fácil. Por um lado, como tema recente, carrega consigo estigma de

\footnotetext{
${ }^{1}$ Está relacionada ao conceito do autor sobre modernização reflexiva que significa a possibilidade de uma (auto) destruição criativa para toda uma era: aquela da sociedade industrial. O "sujeito" dessa destruição criativa não é a revolução, não é a crise, mas a vitória da modernização ocidental (Giddens; Beck e Lash, 1997).
} 
modismo, o que dificulta sua compreensão e posicionamento crítico tanto dos pesquisadores quanto da sociedade civil organizada. De outro lado, apresenta-se como saber e prática bastante inovadores e desafiadores. Assim, a sustentabilidade das cidades precisa ser discutida por todos porque diz respeito ao conviver, ao compartilhar a ao coexistir dos seres da Ecosfera.

Nas décadas de 1970 e 1980, no Brasil, destacaram-se estudos sobre as cidades (realizados por arquitetos, geógrafos e sociólogos), sobre a violência urbana, crescimento populacional, pobreza, favelização, segregação espacial e metropolização das cidades, realizados por pesquisadores como Kowarick (1979), Maricato (1980), Rolnick (1988), entre outros. Já na década de 1990, a globalização concentrou olhares de inúmeros pesquisadores como Santos (2000), Ianni (2000), Sassen (2010) e outros.

Essa multiplicidade de pesquisas indica o forte caráter interdisciplinar impresso no estudo das cidades e uma busca crescente por todas as áreas de atuação pela sustentabilidade das cidades globalizadas, contudo, a sustentabilidade urbana surge no período pós-moderno, de forte e desigual crescimento e desenvolvimento econômico, pela demanda da qualidade de vida, ou pela sua falta, a partir da identificação dos problemas socioambientais urbanos, como, por exemplo, a segregação socioespacial, a poluição, a perda de áreas verdes, a contaminação da água, a questão dos resíduos sólidos, entre outros, e todos eles causas e consequências desse período.

O gestor público e a administração pública, portanto, encontram variáveis novas e desafiadoras para serem consideradas, não bastando apenas construírem mais casas ou prolongarem as redes de água e esgotos, mas também e principalmente pensarem as cidades dentro de um contexto mundial, levando em consideração os elementos ambientais e sociais, como, por exemplo, a gestão por bacias hidrográficas e suas problemáticas interdisciplinares. Uma outra gestão das cidades é, desta forma, necessária e urgente. Uma gestão que integre múltiplos aspectos (sociais, econômicos, ambientais, culturais) e que incorpore a prevenção dos riscos socioambientais urbanos. 
$|248|$

Caminhos da sustentabilidade urbana: o desafio da construção..

\section{Sustentabilidade Urbana}

Para Acselrad (2009), a cidade sustentável é o modelo de civilização sustentável, equitativa, harmoniosa e ancorada nos princípios de justiça social e autonomia individual. Em sua obra A Duração Das Cidades: Sustentabilidade e Risco nas Políticas Urbanas (2009), o autor mostra como o discurso ${ }^{2}$ da sustentabilidade urbana vem sendo usado na gestão das cidades. Diz que esse debate representa um momento da democratização do poder sobre os processos socioambientais nas cidades, apresentando um olhar crítico sobre o chamado pensamento único urbano, que exige dos gestores das cidades que eles se ajustem aos propósitos tidos por inelutáveis da globalização financeira (competitividade, eficiência, crença ilimitada na tecnologia, entre outros,) concebendo a cidade como simples negócio ou mercadoria.

A questão central está em como pensar e construir, no presente, o futuro desejável, democrático e justo das cidades? Nesta direção, Henrique Rattner (2009) no prefácio da obra de Acselrad (2009), ressalta:
O gigantismo das aglomerações urbanas, a complexidade da teia de relações múltiplas, contraditórias e centrífugas e as tensões político- sociais têm constituído o cerne da problemática a

\footnotetext{
2 Segundo Acsreald (2009) existem vários sentidos da sustentabilidade urbana: O da eficiência (neomalthusianos, economistas ecológicos, pessimistas tecnológicos) associam a sustentabilidade ao estabelecimento de limites quantitativos ao crescimento econômico; O da escala - desenvolvimento compatível com a capacidade de suporte do planeta; $\mathrm{O}$ da equidade - ênfase nas necessidades e a asserção de que os pobres são as principais vítimas da degradação ambiental; O da autossuficiência - propostas de preservação e construção das condições de autossuficência econômica de comunidades de produtores ameaçados pela difusão homogeneizadora das relações mercantis e monetárias; O da ética. Evoca critérios éticos sobre o padrão das relações sociais.
} 


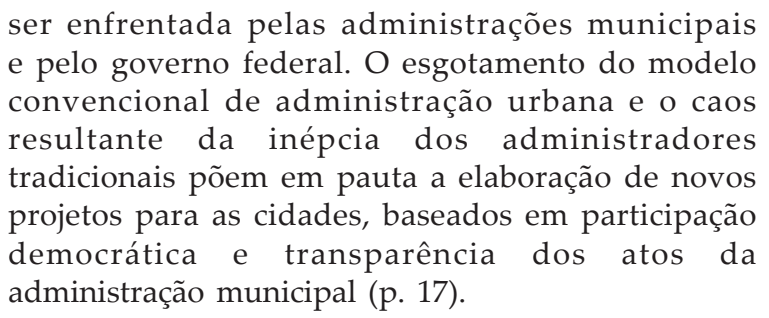

A categoria principal, de pensamento, apontada por Rattner (in Acselrad, 2009, p. 19) é, a de sustentabilidade urbana: “categoria pela qual, a partir da última década do século $X X$, as sociedades têm problematizado as condições materiais da reprodução social, discutindo os princípios éticos e políticos que regulam o acesso e a distribuição dos recursos ambientais - ou, num sentido mais amplo, os princípios que legitimam".

Para explicá-la o autor utiliza os conceitos de meio urbano associado a riscos urbanos, justiça ambiental, modernização ecológica, entre outros. Essa categoria busca explicar as diferenças nos vários discursos políticos que advogam para si o termo sustentabilidade, em torno da gestão urbana das cidades. As escalas de análise são múltiplas: nível global, regional e local.

Para o autor, a concepção hegemônica sobre sustentabilidade urbana ou sustentabilidade urbana prática, como é chamada, constitui uma vontade de tornar a cidade mais funcional para o capital, fazendo durar a cidade em sua materialidade técnica de estoques e fluxos de matéria e energia necessários à acumulação urbana. Existe também outra dimensão desta sustentabilidade, denominada, pelo autor, de retórica, a qual propõe um meio de neutralizar a crítica ambientalista pela incorporação da variável ambiental, atribuindo legitimidade ampliada aos responsáveis pelas políticas públicas urbanas, no contexto da competição global.

Acselrad (2009) analisa a tipologia dos discursos sobre a sustentabilidade urbana, destacando três aspectos: a ênfase na descentralização urbana, a ação de restauração, e a interação dos diversos fatos urbanos. Essas evocações fazem parte do marketing urbano e representam uma forma de ampliar a legitimidade das 
$|250|$

Caminhos da sustentabilidade urbana: o desafio da construção...

políticas públicas por meio da integração dessa tripla dimensão "integração das periferias pela descentralização, de integração da memória pela restauração e de integração dos atores pela interação" (Acselrad, 2009, p. 26).

O conceito de sustentabilidade urbana é discutido por vários autores, representando diferentes abordagens sobre a temática e o desafio maior parece ser como a sustentabilidade se realizará na prática social. "O futuro das cidades dependerá em grande parte dos conceitos constituintes do projeto de futuro dos agentes relevantes na produção do espaço urbano". (Acselrad, 2009, p. 47). Nesse sentido, o autor apresenta, em sua obra, uma coletânea de oito diferentes pesquisadores sobre a sustentabilidade urbana. Seis delas serão parcialmente apresentadas neste artigo.

Barbara Deutsch Lynch (in Acselrad, 2009) discute o papel exercido pelas instituições internacionais para a proteção ambiental e suas implicações para a justiça ambiental em cidades latinoamericanas. Afirma que os programas dirigidos aos cidadãos urbanos da América Latina ainda estão, em grande parte, ligados ao tratamento do lixo, em vez de sua redução, bem como a projetos locais do tipo faça você mesmo, em vez de vigorosos programas municipais concertados.

Rose Compans (in Acselrad, 2009) dedica-se a analisar os antagonismos e complementaridades das cidades sustentáveis e cidades globais como duas representações do espaço-tempo urbano que colocam a sustentabilidade como condição da competitividade. A autora é da opinião de que a noção de sustentabilidade somente apresenta sentido quando é adjetivada - sustentabilidade econômica, ecológica, social, adquirindo maior concretude por um lado e esvaziando-se de seu poder transformador/utópico por outro. A esse respeito a autora infere que

\footnotetext{
falar em cidades sustentáveis e contrapô-las às cidades globais é, nesse sentido, cair em um vazio teórico conceitual. Da mesma forma que a noção de cidades sustentáveis não passa de uma estratégia argumentativa para conferir legitimidade a
} 


\begin{abstract}
determinadas proposições em matéria de política urbana, a noção de "cidades globais" é recuperada para justificar projetos de modernização do espaço construído em face de novos requisitos da acumulação transnacional (p. 151).
\end{abstract}

Pierre Veltz (in Acselrad, 2009) analisa a cidade com destaque para o aspecto das dinâmicas econômicas, a partir de três pontos de vista: a cidade como ator coletivo, a cidade e os atores da economia e o que acontece com a produção econômica da própria cidade. Indica o fenômeno da metropolização e o papel central que este fenômeno desempenha nas economias emergentes, como os exemplos de Hong Kong, Cingapura, Bombaim e São Paulo.

Fernanda Sánchez (in Acselrad, 2009) aborda os discursos e imagens da cidade contemporânea. As demandas que o capital impõe às cidades já não são apenas as da produção, mas também as referentes à informação e à comunicação. Esse processo de produção do espaço social é simultaneamente objetivo e subjetivo. São introduzidas formas modernas de dominação e técnicas de manipulação cultural. Trata-se do city marketing como instrumento de políticas urbanas. Os discursos dos atores hegemônicos que possibilitam realizar os imperativos do capitalismo atual tendem a instaurar um pensamento único. É a transformação das cidades em tecnópoles, em cidades-mercadorias, como o exemplo de Curitiba.

Fabrício Leal de Oliveira (in Acselrad, 2009) debate o tema da agenda hegemônica para as cidades do século XXI sobre as bases da sustentabilidade e competitividade. Afirma que o planejamento estratégico de cidades (PEC) - a tradução da gestão empresarial para o setor público - vem ganhando crescente visibilidade como opção das administrações públicas locais para enfrentar os desafios criados pelas transformações em curso no mundo contemporâneo. A base do pensamento e da ação estratégica estaria lastreada na identificação das forças, fraquezas, oportunidades e ameaças de uma empresa em relação a seu ambiente de ação, assim como no 
$|252|$

Caminhos da sustentabilidade urbana: o desafio da construção...

processo de estabelecimento de uma estratégia frente a essas questões segundo metas e objetivos definidos.

A partir disso, dá-se a despolitização das relações entre o poder público local e a elite empresarial, assim como a desqualificação da política que macularia as relações entre o governo local, o governo nacional e os partidos políticos, o que, segundo o autor, remete a uma representação tecnomaterial da cidade e a uma gestão erudita do território.

Por fim, Rosa Moura (in Acselrad, 2009) apresenta os riscos da cidade-modelo, destacando o exemplo de Curitiba que está inserida neste rol. Descreve uma historia de mais de trinta anos, nos quais a construção simbólica de um cenário de eficácia e perfeição vem impedindo descortinar os bastidores de uma realidade comum, brasileira, com belezas e mazelas. Argumenta que o processo de metropolização de Curitiba estimulou o êxodo rural e a ocupação do espaço metropolitano se deu seletivamente: o valor da terra e da moradia e o custo das melhorias urbanas reservaram para Curitiba um morador com melhores níveis de renda, direcionando os grupos empobrecidos e os migrantes de menor poder aquisitivo para as áreas periféricas internas e de outros municípios. Ou seja, os segmentos sociais mais pobres foram expulsos para a periferia. Os conflitos e as contradições sociais e econômicas são encobertos pela visão superficial da cidade modelo.

\subsection{A Governança Social e Pública}

Seria impraticável buscar a sustentabilidade urbana sem compreender as influências dos fatores políticos no gerenciamento das cidades, e alcançar os princípios de um modelo transparente e responsável de Governança.

Dowbor (2002) apresenta o termo Governança como um conceito que expressa a articulação política de grupos de interesses que representam alternativas àquelas baseadas no centralismo decisório unidirecional, propondo uma gestão mais dialógica por meio da distribuição de poder entre os atores, transparência e controle (mútuo) sobre decisões e ações. 
Fischer (1996, p. 19), entende que "governance [governança] é um conceito plural, que compreende não apenas a substância da gestão, mas a relação entre os agentes envolvidos, a construção de espaços de negociação e os vários papéis desempenhados pelos agentes do processo".

Segundo ela, quando a governança ocorre no âmbito das organizações de mercado, é denominada de governança corporativa. Quando se operacionaliza no âmbito das organizações ou interorganizações da sociedade civil (terceiro setor) atribui-se o nome de governança comunitária. Quando esse processo se dá no âmbito das organizações públicas estatais, em um ou mais níveis federativos, atribui-se o nome de governança pública e quando é praticada em arranjos organizacionais de composição plural, envolvendo agentes estatais e não estatais, públicos e privados com ou sem fins lucrativos para a cogestão da coisa pública (defesa de interesses públicos, coprodução de bens e serviços para a promoção do bem-estar social), denomina-se governança social.

Maria da Conceição Marques (2007) destaca que o conceito de governança está relacionado ao de "accountability", ou seja, de responsabilidade na gestão. por meio dela busca-se abranger assuntos relativos a controle e direção de uma empresa ou de outras esferas, como as de uma sociedade, por exemplo, sem intervir nas suas autonomias mas equilibrando as suas competitividades e produtividades por meio de um modelo transparente e responsável de gestão.

Para Martins (1998) a governança social refere-se a interação ou, como chama de arranjo institucional baseado na regulação, das três esferas sociais (estado, mercado e sociedade civil) para o bem-estar social por meio da produção e consumo de bens públicos e privados. Enfatiza que:

Um traço característico desta visão de governação social é o imperativo da interação, cooperativa e competitiva [competição administrada], e a necessidade de ação orquestrada, regulada, da busca de alianças e outras 
$|254|$

Caminhos da sustentabilidade urbana: o desafio da construção..

formas integrativas, de tal modo que os interesses e o potencial de ação das três esferas (Estado, terceiro setor e iniciativa privada, enquanto campos ou núcleos de diferentes racionalidades) possam ser satisfeitos de forma não segregatória (Martins, 1998, p. 3).

Marques (2007, p. 6), na figura 1, ilustra a relação dos elementos da governança pública, fornecendo um "mix apropriado de conformidade e performance". para a autora, a governança pública requer a definições claras das responsabilidades, conhecimento e entendimento da relação entre os sujeitos e atores sociais, sustentação da gestão pelos níveis hierárquicos superiores.

Figura 1: Elementos da governança das entidades públicas

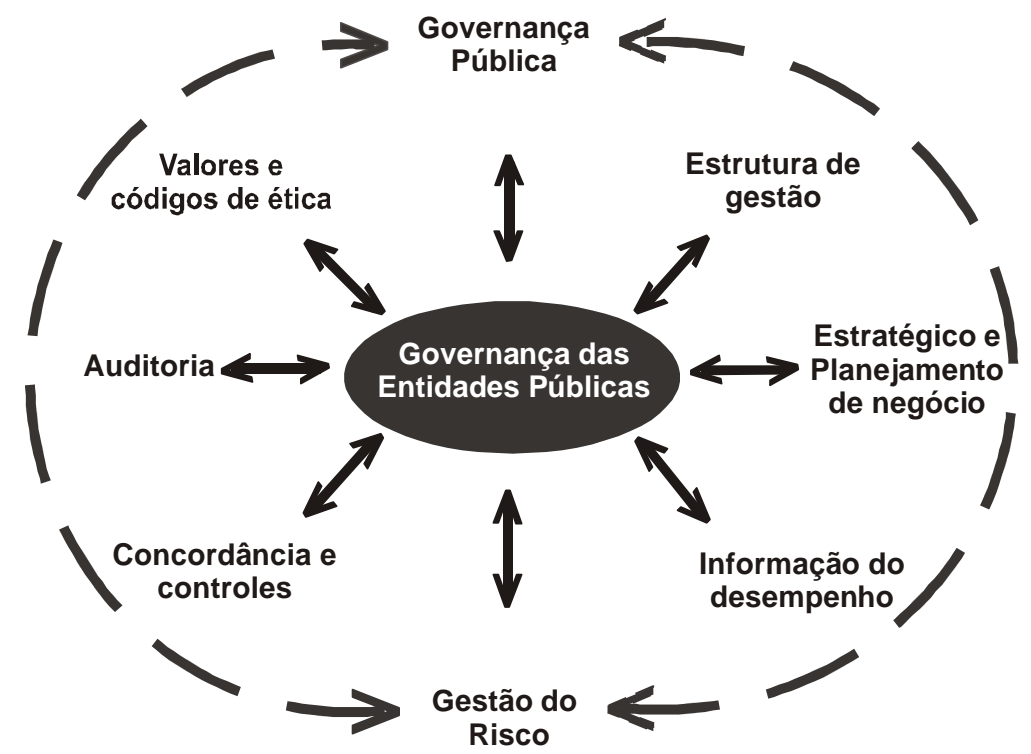

Fonte: Adaptado de ANAO, Apud Barret, P. (2003). Achieving Better Practice Corporate Governance in the Public Sector. AM Auditor General for Australia. Recuperado em 27 October, 2003, de http://www.anao.gov.au/uploads/documents/ 


\section{Cinco são os princípios pessoais e estratégicos da governança pública:}

Liderança - A governança do sector público requer liderança [...] lúcida e transparente comunicação com o Ministro e o estabelecimento de prioridades governamentais de modo claro.

Compromisso - As melhores práticas de governança pública requerem um forte compromisso de todos os participantes.[...] Isto exige uma boa orientação das pessoas, que envolve uma comunicação melhor; uma abordagem sistemática à gestão da organização; uma grande ênfase nos valores da entidade e conduta ética; gestão do risco; relacionamento com os cidadãos e os clientes e prestação de serviço de qualidade.

Integridade - A integridade tem a ver com honestidade e objectividade, assim como altos valores sobre propriedade na administração. Ela é dependente da eficácia do controlo estabelecido e dos padrões pessoais e profissionalismo dos indivíduos dentro da organização.

Responsabilidade - Os princípios da governança requerem de todos os envolvidos que identifiquem e articulem as suas responsabilidades e as suas relações; considerem quem é responsável por quê, perante quem, e quando; Transparência A transparência é essencial para ajudar a assegurar que os corpos dirigentes são verdadeiramente responsáveis. A International Federation of Accountants realça que "a transparência é uma atitude e uma crença entre os intervenientes chaves, políticos, funcionários públicos e outros stakeholders, a quem a informação tem de ser exibida, e não é detida por qualquer entidade particular - ela é um recurso público".

Integração - o desafio real da governança é o de garantir que os envolvidos estão holisticamente integrados dentro de uma abordagem da organização, e bem compreendida e aplicada dentro das 
$|256|$

Caminhos da sustentabilidade urbana: o desafio da construção...

entidades. A governança corporativa pode providenciar a integração do quadro de gestão estratégica, necessária para obter os padrões para atingir as suas metas e objectivos (Marques, 2007, pp. 10-11).

Butler (1999) apud Marques (2007) destaca alguns aspectos da governança pública e corporativa: separação entre os papéis dos poderes públicos; conselho de diretores não executivos, comitê de auditoria não executiva formado por auditores externos; códigos de ética adotados; identificação do risco e gestão do risco.

“É importante que um gestor no sector público saiba controlar os riscos associados à sua posição na administração pública, pelo que uma análise governamental se mostra como ferramenta útil para se alcançar isso" (Butler, 1999 apud Marques, 2007, p. 24). Apesar do citar riscos de forma abrangente, entender que a gestão dos riscos socioambientais, por meio dos cinco princípios da governança pública torna-se fundamental para se trilhar os caminhos da sustentabilidade urbana.

\subsection{A Gestão dos Riscos Socioambientais Urbanos}

Discorrer sobre sustentabilidade urbana significa também incorporar a questão das mudanças globais, os riscos e seus componentes, além da questão da vulnerabilidade e resiliência, temas abordados pelos vários autores na obra $A$ Duração das Cidades, organizada por Acselrad (2009), como exposto no Item 4 acima. Nela, o conceito de risco é associado aos riscos urbanos que representariam a cristalização do discurso do pensamento único em torno da sustentabilidade urbana existente apenas na retórica, fortalecendo a desigualdade social e econômica, que tentam mascarar a violência, a pobreza e os problemas socioambientais existentes. Como foi abordado anteriormente, os autores apontam alguns caminhos para que a sustentabilidade urbana possa ser desenvolvida na gestão urbana das cidades, por meio de uma maior participação social nesse processo. 
A participação social como indicadora de sustentabilidade na gestão urbana também ganha destaque na análise de Veyret (2007), principalmente no que se refere à gestão do risco. A autora faz uma análise aprofundada e atual da noção de risco ${ }^{3}$, sua representação, atores e relações com o espaço, práticas de gestão de organização do território às operações pós-catástrofe e reconstrução.

O risco, objeto social define-se como a percepção do perigo, da catástrofe possível. Ele existe apenas em relação a um indivíduo e a um grupo social ou profissional, uma comunidade, uma sociedade que apreende por meio de representações mentais e com ele convive por meio de práticas específicas. (...) Correm-se riscos, que são assumidos, recusados, estimados, avaliados, calculados" (Veyret, 2007, p. 11).

Pensar em gestão urbana dos riscos é, para a autora, antes de tudo, incorporar a percepção das comunidades sobre o espaço onde moram. De nada adiantará o levantamento das áreas de risco e o desenvolvimento de programas de prevenção, pelo poder público, sem o envolvimento efetivo da população local, que, ao participar, pensará e proporá estratégias de monitoramento do lugar, bem como a desocupação das áreas de risco, em conjunto, por meio da gestão participativa. É importante também destacar que cabe ao poder público a missão de oferecer condições dignas de moradia e acesso à habitação à população e não apenas mitigar os riscos de forma paliativa, como vem sendo feito há décadas nas metrópoles brasileiras.

\footnotetext{
${ }^{3}$ Segundo Yvette Veyret (2007), o risco é definido como uma ameaça que pode ser percebida de forma individual ou coletiva, sobre bens móveis ou imóveis, e esta percepção dependerão do local de sua ocorrência, da época e da cultura da população, uma vez que é subjetiva. A autora também relaciona o risco com a geografia, na medida em que este se realiza dentro de um espaço geográfico, qualquer que seja o tipo de risco.
} 
$|258|$

Caminhos da sustentabilidade urbana: o desafio da construção..

Outro aspecto relacionado aos riscos socioambientais urbanos diz respeito ao acentuado grau de ocorrência e amplitude de eventos perigosos nas cidades, associados às mudanças climáticas globais. Giddens (2010) estuda este tema em sua obra "A política da mudança climática". O autor evidencia que "para enfrentar o aquecimento global, é preciso introduzir na política uma perspectiva de longo prazo. Tem que haver algum tipo de planejamento" (Giddens, 2010, p. 25).

Assim, Giddens incentiva que as políticas públicas voltem a adotar o planejamento como sua estratégia de ação e que este planejamento deve estar pautado na sustentabilidade urbana. Contudo, não defende um planejamento autoritário, como aquele realizado no período pós-guerra, que caiu em descrédito devido a suas imensas falhas. Giddens (2010) defende uma maior intervenção estatal, de um Estado assegurador, por meio de um planejamento conciliado com as liberdades democráticas, e que saiba, sobretudo, lidar com riscos e incertezas.

O debate sobre os riscos ganha mais brilho e intensidade com as análises de Hogan e Marandola (2009), que trazem a dimensão humana para a gestão de riscos socioambientais, interligando a preocupação com o aspecto social, destacado por Acselrad e Veyret, ao contexto das mudanças climáticas, exposto por Giddens. A obra "População e mudança climática: dimensões humanas das mudanças ambientais globais", organizado pelos autores, dos quais participam pesquisadores que integram o Núcleo de Estudos de População - NEPO, apresenta, como seu principal objetivo, a necessidade de "oferecer caminhos para as ciências humanas, em especial para os estudos de população, no seu esforço de lidar com as mudanças climáticas" (Hogan e Marandola, 2009, p. 18). Para os autores,

Risco é um conceito importante porque permite pensar em termos de probabilidades tanto no que se refere à frequência quanto aos lugares de ocorrência. Permite, portanto, promover o planejamento a partir de um olhar prospectivo. (...) Perigo é entendido 


\begin{abstract}
enquanto o evento em si, o hazard, é o conceito utilizado para delimitar os eventos que produzem o rompimento de uma continuidade, que interrompem uma sequência, provocando danos na interface população-ambiente. (...) Riscos e perigos, portanto, referem-se ao mesmo fenômeno, sendo apenas léxicos que permitem pensar momentos distintos do processo. (...) O uso de um ou do outro termo no discurso acadêmico e político refere-se à ênfase que se direciona às ações preventivas pré-evento (risco) e à compreensão do processo de produção e distribuição dos eventos (perigos), (pp. 36-37).
\end{abstract}

Todavia, para se pensar a gestão dos riscos socioambientais urbanos é necessário também compreender a questão da vulnerabilidade socioambiental. Para Acselrad (2009, p. 39) "o que caracteriza as cidades contemporâneas, sob os efeitos da globalização, é justamente a profunda desigualdade social na exposição aos riscos ambientais", que se pode definir como vulnerabilidade socioambiental.

Para Hogan e Marandola (2009) pensar essa vulnerabilidade é pensar no objeto dela (vulnerabilidade a quê?), além do quem é vulnerável e onde, pois alguns perigos atingem grupos sociais e demográficos diferentes, ao mesmo tempo em que recaem sobre locais com formações paisagísticas e ecológicas também diversas. “Em algumas situações o risco será o mesmo, e até a ocorrência dos perigos e impactos será igual, mas a forma como atingirão lugares e populações será distinta. Isso é o salto que a ideia de vulnerabilidade permite dar nas análises" (Hogan e Marandola, 2009, p. 38).

Complementando essa ideia, Lavell e Ortega (2009, p. 16), acreditam que "toda a causa de vulnerabilidade e toda a expressão de vulnerabilidade é social. Portanto, o processo de criação de condições de vulnerabilidade obedece também a um processo de construção social. Assim, o problema do risco de desastre não está localizado na esfera dos eventos realmente extremos, mas sim nos eventos recorrentes para os quais, em princípio, a sociedade 
$|260|$

Caminhos da sustentabilidade urbana: o desafio da construção..

poderia ter disponível mecanismos de planejamento, de proteção ou de mitigação, desde que não houvesse problemas de cunho social e econômico.

Para os autores a predisposição ao dano, ou seja, a vulnerabilidade dos elementos socioeconômicos expostos ao mesmo, com referência ao espectro normal de eventos físicos recorrentes é resultado de condições sociais, políticas e econômicas que assinalam os diversos níveis de debilidade de determinados grupos sociais.

Veyret (2007) segue esse mesmo raciocínio, complementando que a vulnerabilidade tem relações com aspectos físicos, ambientais, técnicos, econômicos, psicológicos, sociais e políticos. A vulnerabilidade expressa a fragilidade de um sistema em superar uma crise provocada por um perigo. No caso das cidades, a vulnerabilidade pode ser considerada o resultado de uma política urbana que não conseguiu controlar a ocupação do espaço em razão das pressões financeiras, como o mercado imobiliário. O outro lado da vulnerabilidade, ou seja, a capacidade de um sistema complexo (as cidades) para se restabelecer e melhorar sua reatividade após uma catástrofe, é o que se denomina de resiliência.

Pelling (2003), em sua obra "Vulnerabilidade das Cidades", estuda a resiliência. $\mathrm{O}$ autor analisa os fatores de risco existentes nas cidades, identificando um paralelo entre o histórico dos riscos e desastres urbanos e as vulnerabilidades a tais riscos, sejam pelas características do local ou por questões econômicas, sociais e políticas. Vai além do diagnóstico dos desastres e aborda formas de criar cidades mais seguras, incorporando o conceito de resiliência ${ }^{4}$ e procurando uma urbanização sustentável.

Segundo Pelling (2003), a resiliência pode ser vista como a capacidade dos grupos e comunidades de se adaptarem e minimizarem seus graus de vulnerabilidade, sobretudo em

${ }^{4} \mathrm{O}$ autor analisou a resiliência de grupos sociais com diversidade de contextos políticos, culturais, sócio-econômicos e físico-territoriais, como Bridgetown, Barbados; Georgetown, Guyana; e Santo Domingo, República Dominicana. 
ambientes de maior pobreza, onde recursos financeiros e físicos são muito limitados, por meio da coesão, participação política e lutas sociais, construindo a resiliência em nível local e, assim, ampliando seu potencial de adaptação em nível local.

Pelling (2003) argumenta que a resiliência social é um conceito que pode se mover entre a teoria, os aspectos políticos da urbanização e do desastre. A resiliência incorpora, assim, a noção de potencial de adaptação como resposta para a vulnerabilidade humana e política local (individual para global) até o centro da análise e prática em busca de uma urbanização sustentável.

O conceito de resiliência contribui para todo o debate exposto, pois evidencia a complexidade das sociedades que não podem ser vistas como uniformes e estáticas. Cada grupo social possui (e desenvolve) características e mecanismos diferentes dos outros grupos perante os riscos cotidianos da vida e de se viver. Nesse sentido, a gestão das cidades precisa ser pensada como algo dinâmico e vivo, incorporando toda a diversidade existente na sociedade, em suas esferas cultural, social, ambiental, econômico, político, entre outras.

Também não se pode tratar do conceito de risco sem analisar as importantes mudanças globais instauradas a partir do fenômeno da globalização. Sob essa ótica de Saskia Sassen (2007), em sua obra "Uma sociologia da globalização", dois conjuntos de processos constituem a globalização: One is the set of global institutions, such as the World Trade Organization, global financial markets, the War Crimes Tribunals and the new global cosmopolitanism. o conjunto de instituições globais, como a Organização Mundial do Comércio (OMC), os mercados financeiros globais, os novos cosmopolitas e o Tribunal Internacional de Crimes de Guerra; e um segundo conjunto de processos que ocorrem em nível nacional e local, como a política monetária e fiscal do Estado, as intervenções do Fundo Monetário Internacional (FMI) e dos Estados Unidos, e as redes de ativistas engajados em lutas locais, os quais muitas vezes são ignorados pela maioria dos cientistas sociais. 
$|262|$

Caminhos da sustentabilidade urbana: o desafio da construção...

A autora enfatiza que a intervenção do Estado e da sociedade deve levar em conta as dimensões dos processos que transitam entre as escalas globais e locais. Os processos transnacionais como a globalização econômica, política e cultural trazem uma série de desafios teóricos e metodológicos às ciências sociais. O global transcende o quadro exclusivo dos Estados Nacionais, mas, de modo simultâneo, habita parcialmente territórios e instituições nacionais.

Faz-se necessário, portanto, distinguir as diferentes escalas que se constituem por meio de processos e práticas globais e conteúdos e localizações institucionais locais específicas. As dualidades nacional/global e local/global dão lugal a uma globalização multiescalar como, por exemplo, as comunidades transnacionais, cidades globais, cadeias de produção de bens e compressão espaçotemporal. As estruturações do global dentro do nacional, portanto, acarretam uma desnacionalização parcial e tipicamente muito especializada e específica de certos componentes do nacional (Sassen, 2010).

Segundo Sassen (2010), atualmente, vive-se uma desvinculação parcial do espaço nacional e das hierarquias tradicionais de escala centradas no nacional, com a cidade encaixada em algum ponto entre o local e a região. A cidade, aqui, não é uma unidade limitada, mas uma estrutura complexa que pode articular uma variedade de processos transfronteiriços e reconstituí-los como uma condição parcialmente urbana.

Portanto, com o cuidado da não simplificação reducionista, entende-se que a gestão dos riscos socioambientais urbanos assume distintos, porém complementares enfoques se considerada a complexidade do tema, de acordo com as abordagens epistemológicas.

\section{Considerações finais}

A análise dos autores apresentados nesse artigo demonstrou que a sustentabilidade urbana ainda encontra-se em um nível muito mais discursivo do que de ação pragmática. $\mathrm{O}$ conceito de 
sustentabilidade urbana enquanto sistema que respeita e representa o equilíbrio entre as três dimensões: econômica, social e ambiental é desmistificado por Acserald (2009) quando este assim o denomina "constitui uma vontade de tornar a cidade mais funcional para o capital, fazendo durar a cidade em sua materialidade técnica de estoques e fluxos de matéria e energia necessários à acumulação urbana". Ou seja, é incorporado pelo mercado que o trata como mais um produto ou serviço a ser vendido, afastando-se da ideia inicial.

A complexidade do tema aumenta quando se incorpora a relação das mudanças globais, os riscos e seus componentes, além da questão da vulnerabilidade e resiliência Há pesquisadores, como Acselrad (2009) que entendem a gestão urbana das cidades é construída por meio de uma maior participação social nesse processo. Junto a ele encontram-se Veyret (2007) e Lavell e Ortoga (2009) que incorporam a percepção social do risco em relação ao espaço onde as comunidades moram, Pelling (2003) que aborda formas de criar cidades mais seguras, incorporando o conceito de resiliência social para uma urbanização sustentável, Hogan e Marandola (2009), que trazem a dimensão humana para a gestão de riscos socioambientais, interligando a preocupação ambiental com aspectos sociais.

Outros pesquisadores tentem a uma abordagem mais política desta gestão como é o caso de Giddens (2010) que assume uma abordagem sistêmica de relações entre as climáticas com as políticas, incentivado a adoção do planejamento a pautar a sustentabilidade urbana e de Sassen (2007) que faz uso do fenômeno da globalização e pontua as escalas global, regional, local nas interações entre o Estado e a Sociedade.

Essas ideias fazem supor que seria impraticável buscar a sustentabilidade urbana sem compreender as influências dos fatores políticos no gerenciamento das cidades, e alcançar os princípios de um modelo transparente e responsável de governança. Dessa forma, pode-se apontar a governança como elemento essencial para a gestão dos riscos socioambientais urbanos, 
$|264|$

Caminhos da sustentabilidade urbana: o desafio da construção..

utilizando-se os cinco caminhos apontados por Marques (2007, pp. 10-11) como princípios pessoais e estratégicos da governança pública (liderança, compromisso, integridade, responsabilidade e integração). Assim, as cidades, palco de contradições e disputas territoriais, simbólicas, culturais e políticas, vivenciarão o exercício da governança e da cooperação como marcos de sustentabilidade e contribuirão para a construção de formas de se pensar o planejamento urbano políticoadministrativo mais justo e sustentável.

\section{Bibliografia}

ACSELRAD, H. A duração das cidades: Sustentabilidade e risco nas políticas urbanas. $2^{\mathrm{a}}$ ed. Henri Acselrad (org.). Rio de Janeiro: Editora DP\&A/ Lamparina, 2009.

BECK, U. La sociedad del riesgo. Hacia una nueva modernidad. Barcelona: Ediciones Paidós Ibérica, 308 p. 1998.

BUTLER, B. "Corporate Governance in the Public Sector". Annual Public Sector Symposium - Queensland, Australia, 4. Retrieved June 16, 2004, from http/ /www.cmc.qld.gov.au/ library. In: MARQUES, M. da C. Aplicação dos Princípios da Governança Corporativa ao Sector Público. RAC, v. 11, n. 2, abr./ jun. 2007, pp. 11-26, 1999.

DOWBOR, L. Parcerias e alianças: O bom senso na gestão social. Uma abordagem conceitual das políticas para crianças e adolescentes. São Paulo, Documento para discussão.2002.

FISCHER, T. “Gestão contemporânea, cidades estratégicas: Aprendendo com fragmentos e reconfigurações do local". In: FISCHER, T. (org.). Gestão estratégica: Cidades estratégicas e organizações locais. Rio de Janeiro: FGV.1996.

GIDDENS, A. A política da mudança climática. Rio de Janeiro: Jorge Zahar Editores, 2010. 
Corina A. B. Carril Ribeiro, Rafaela Antunes Fortunato, Claudia Cristina L. Machado

HOGAN, D. J. e MARANDOLA Jr., E. (orgs.). População e Mudança Climática: Dimensões Humanas das Mudanças Ambientais Globais. Campinas: Nepo/UNFPA, 2009.

LAVELL, A. e ORTEGA, G. P. La gestión del riesgo de desastres: Un enfoque basado en procesos. Lima: Secretaría General de la Comunidad Andina. Disponível em: www.comunidadandina.org, acesso em 28/06/2011. 2009.

KOWARICK, Lucio. A espoliação urbana. Rio de Janeiro: Paz e Terra, 1979.

MARICATO, E. Loteamentos clandestinos. In: Módulo 60 set/80. Rio de Janeiro: Avenir, 1980.

MARQUES, M. da C. "Aplicação dos Princípios da Governança Corporativa ao Sector Público". RAC, v. 11, n. 2, abr./jun. 2007.pp. 11-26.

MARTINS, H. F. Publicização e Organizações Sociais: construindo organizações multicêntricas. In: III Congresso Internacional do Centro Latinoamericano de Administração para o Desenvolvimento, Madrid, 1998. pp. 1-11.

PELLING, M. The Vulnerability of Cities. Natural Disasters and Social Resilience. London: Earthscan Publications Ltd., 2003.

ROLNICK, R. O que é cidade? São Paulo: Brasiliense, 1988.

SANTOS, M. Por uma outra globalização: Do pensamento único a consciência universal. São Paulo: Record, 2000.

SASSEN, S. 2007. A sociology of globalization. New York: W. W. Norton \& Company Ltd., 2007.

VEYRET, Y. Os riscos: O homem como agressor e vítima do meio ambiente. Yvette Veyret (org.). São Paulo: Editora Contexto, 2007. 